\title{
An Investigation Into the Impact of Limiting Carbon Emissions on the Korean Power System and the Electricity Market
}

\author{
Changseob Kim* and Hyeongon Park ${ }^{\dagger}$
}

\begin{abstract}
To address mounting concerns over global warming, the Paris Agreement was reached in December 2015, which aims to limit the increase in global average temperature. South Korea has set a highly ambitious target to reduce emissions and submitted an Intended Nationally Determined Contribution (INDC). Based on the INDC, we investigated the impact of limiting carbon emissions on the power system and the electricity market in Korea. Through detailed simulations on assumed plausible scenarios, this work highlights a) the effects of different carbon emission targets on the annual carbon emission volumes, generation costs, and carbon price; b) the generation mix changes induced by carbon emission limits; and c) the difference in system marginal price and payments for generator owners that carbon emission constraint creates in electricity markets under three different pricing rules.
\end{abstract}

Keywords: Carbon emission reduction, Electricity market, Paris Agreement, Post-2020 climate plans

\section{Introduction}

The Paris Agreement, an agreement within the United Nations Framework Convention on Climate Change (UNFCCC) dealing with greenhouse gas emissions, was adopted in December 2015 [1]. The aims of the Paris Agreement were to limit the global average rise in temperature to well below $2^{\circ} \mathrm{C}$ and to pursue efforts to limit a global average rise of $1.5^{\circ} \mathrm{C}$ [1]. To accomplish this, countries have announced their post-2020 climate plans to reduce greenhouse gas emissions to the international community and have submitted Intended Nationally Determined Contributions (INDCs) [2].

South Korea submitted an INDC with a target of a 37\% reduction relative to a "business as usual" (BAU) emission level in 2030. However, as of October 2016, specific measures and scenarios for emission mitigation and the assignment of targets to individual sectors have not yet been published. More specifically, the South Korean government has only presented a broad framework that includes the total reduction target (37\%), the volume of reduction that can be achieved through purchasing carbon emission rights from abroad (11.3\%), and the limitations to reducing carbon emissions in the industrial sector (less than $12 \%)[3,4]$.

Here, we establish an appropriate reduction target for the power sector and examine the relevant scenarios and impacts of carbon emission limits on the power system and electricity market. The power sector was the focus of this work, because this is one of the largest carbon emitters and

$\dagger \quad$ Corresponding Author: Dept. of Statistics, Seoul National University, Korea. (hyeongon@snu.ac.kr)

* Dept. of Energy IT, College of Engineering, Gacheon University, Korea. (cskim407185@gmail.com)

Received: November 4, 2016; Accepted: February 17, 2017 faces greater uncertainty related to the carbon emission problem.

The construction of new nuclear power plants and the expansion of transmission lines have been discussed as methods to reduce carbon emissions; however, these approaches are not considered in this study for the following reasons [5-7]. 1) The public is increasingly concerned about exposure to electric and magnetic fields. The generation of these fields with the flow of electrical current has limited the acceptance of new transmission line installations. 2) Building new nuclear power plants raises concerns about major accidents and environmental issues associated with radioactive waste disposal. The opposition is expected to be amplified by the recent large earthquake occurring in the Kyongnam region.

While discarding these two methods, we consider other feasible methods (e.g., applying a realistic load pattern in load forecasting, new technologies to reduce carbon emissions, and encouraging the use of renewable energy resources). Thus, in an effort to understand the impact of carbon emission constraints on the power system and electricity market, this study was carried out based on two targets for the power sector: $24.85 \%^{1}$ and $30.09 \%$. The first target of $24.85 \%$ indicates the base scenario that the domestic carbon emission target is equally assigned to all sectors. In other words, all sectors that generate carbon emissions should lower their emissions by the same ratio. The second target of $30.09 \%$ represents a more realistic scenario, reflecting the potential of each sector to reduce carbon emissions and the expense related

\footnotetext{
The target value $24.85 \%$ means that the power sector should reduce carbon emission volumes by as much as $24.85 \%$ of the BAU emission level. That is, the power sector can produce $75.15 \%$ of BAU carbon emission.
} 
to carbon reduction techniques for each sector. Explicitly, considering the additional costs incurred due to carbon emission limits and national industrial competitiveness, it is appropriate to assign $45 \%$ of the total carbon emission volume to the power sector. This overall volume represents a carbon emission reduction target for the power sector of $30.09 \%$ [8-11]. ${ }^{2}$

The main contributions of this work are as follows:

- A mathematical formulation is proposed to investigate the effects of carbon emission constraints on the power system and the electricity market.

- Various plausible scenarios for the future power system (e.g. load forecasts, an annual carbon emission reduction target, new carbon emission technologies) are described.

- The possible electricity markets in the future based on Korean government's reports are explained. Because there are uncertainties in predicting how the price of carbon emissions is reflected in the electricity market, we carried out a case study on three different market structures. Detailed results such as system marginal price (SMP), carbon emission price and total generation cost are presented, analyzed, and discussed.

The remainder of this paper is organized as follows. Section 2 provides a mathematical formulation of the problem. In Section 3, a case study is described and discussed. Section 4 details the case study results through the simulation. Finally, Section 5 summarizes our findings and conclusions.

\section{Mathematical Formulation}

The optimization problem is proposed to simulate the effect of carbon emission constraints on the power system and electricity market. In the problem, we introduce a new constraint that can limit annual carbon emissions. Because the load varies continuously, it needs to represent the load at each year. The load level is calculated as follows. First, a future load pattern is generated based on the 2015 historical data and the 7 th Basic Plan report published by Korean government [12]. The load duration curve (LDC) is derived from this forecasted load data for every quarter. The LDC is then linearized and the corresponding linear line is divided into ten sets of blocks, where block is defined as $p$. Finally, the average of each block is computed and set as the representative load level at a block. One example is shown in Fig 1; here the LDC of Q1 in 2015 is shown as a solid line and its approximated value as a dashed line.

Considering the load as mentioned above, the proposed

\footnotetext{
${ }^{2}$ Here, $45 \%$ is obtained by roughly averaging the values from developed countries, such as England (54\%), Germany (45\%), Japan (39.9-41.1\%), and Australia (about 50\%)
}

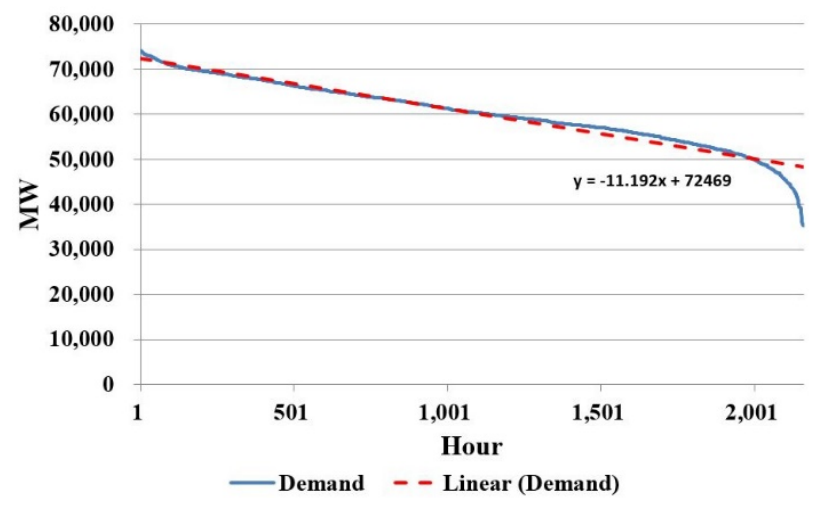

Fig. 1. Load duration curve of Q1 in 2015

mathematical model is formulated as a linear programming (LP) problem, defined by an objective function (1) and constraints (2-4) [13]:

$$
\min \sum_{y \in \mathbf{Y}} \sum_{q \in \mathbf{Q}} \sum_{p \in \mathbf{P}} \sum_{i \in \mathbf{G}} A C(i) / T L F(i) \cdot P(i, y, q, p)
$$

subject to:

$$
\begin{gathered}
\sum_{i \in \mathbf{G}} P(i, y, q, p)=\operatorname{Load}(y, q, p) \\
\sum_{q \in \mathbf{Q}} \sum_{p \in \mathbf{P}} \sum_{i \in \mathbf{G}} C E F(i) \cdot P(i) \leq C E F M A X(y) \\
(i, y, q, p) \in \mathbb{F},
\end{gathered}
$$

where

$$
\begin{aligned}
& A C(i) \quad: \text { average generation cost of generator } i ; \\
& T L F(i) \quad: \text { transmission loss factor of generator } i ; \\
& P(i, y, q, p): \text { generation output of generator } i \text { at block } \\
& p \text { at quarter } q \text { in year } y \text {; } \\
& \operatorname{Load}(y, p, q): \text { load at block } p \text { in quarter } q \text { in year } y ; \\
& C E F(i) \quad: \text { carbon emission factor of generator } i \text {; and } \\
& C E F M A X(y): \text { maximum limit of carbon emission in } \\
& \quad \text { year } y .
\end{aligned}
$$

The objective of the problem was to minimize the average generation cost during the period of observation. Constraint (2) indicates that the active power balance should be maintained at block $p$ in quarter $q$ in year $y$. According to (3), the sum of carbon emissions from all generators should be within the allowable emission level. This constraint is applied to every year. The constraint shown in (4) is a concise form that considers other constraints, such as the power output limit of generators, the minimum up and down time, reserves, the thermal constraint for cogeneration plants, and the power flow constraint $[14,15]$.

The characteristics of cogeneration plants should be taken into account when incorporating a regional cogeneration system into the optimization problem. A cogeneration plant must produce electrical power regard- 
less of the market-clearing price to provide thermal energy needs. Because this situation usually occurs during winter, we incorporated different levels of thermal constraint for different quarters; tighter constraints were applied during Q1 and Q4.

On the other hand, for simplification of the problem, the power flow constraint was only applied to metropolitan areas $^{3}$ and between Jeju Island and the Korean main land. Additionally, we replaced the power flow equations with the DC power flow model in order to avoid solving a complex non-linear, non-convex problem, which is widely used in current electricity markets [16].

\section{Case Study}

\subsection{Load scenario}

This subsection describes the possible load scenarios used for the case study. Building the appropriate load scenario is highly important because it changes the carbon emission mitigation target and the effects of the carbon emission constraints significantly.

It was assumed that the load would increase as shown in Fig. 2 and Table 1. The electricity consumption in 2030 is forecast to be $663,452 \mathrm{GWh}$, in which the average annual growth rate is $2.1 \%$. This forecast value is lower than the data contained in [17], which reported an expected electricity consumption in 2030 of $762,200 \mathrm{GWh}$. In this work, we considered that reference [17] was published in 2014 and that the rate of increase in the load is currently expected to be less than the value described in that study. Hence, the load forecast was adjusted; the actual power



Fig. 2. Load scenarios

Table 1. Load scenarios (GWh)

\begin{tabular}{c|c|c|c|c|c|c|c}
\hline Year & 2017 & 2018 & 2019 & 2020 & 2021 & 2022 & 2023 \\
\hline Load & 532,622 & 555,280 & 574,506 & 588,352 & 600,063 & 609,822 & 617,956 \\
\hline Year & 2024 & 2025 & 2026 & 2027 & 2028 & 2029 & 2030 \\
\hline Load & 625,095 & 631,653 & 637,953 & 644,021 & 650,159 & 656,883 & 663,452 \\
\hline
\end{tabular}

${ }^{3}$ The Kyungin area is the demand center, where power is supplied by base-load generators through the transmission lines. demand for 2030 was determined to be lower than the value proposed in [17].

\subsection{Carbon emission reduction target}

As described in Section 1, the carbon emission reduction targets for the power sector in 2030 are as follows.

1) Scenario 1 ( $\mathrm{sc} 1)$ : the carbon emission reduction target is $24.85 \%$ in 2030 .

2) Scenario 2 ( $\mathrm{sc} 2$ ): the carbon emission reduction target is $30.09 \%$ in 2030 .

It is important to note that, because carbon emission problems are likely to occur after 2020 , it is also necessary to establish proper targets for the period from 2020 to 2030. Therefore a reduction rate that increases at the same rate every year for ten years was calculated, as shown in Fig. 3.

Using the target reduction rate, the annual maximum limit of carbon emission is computed as follows:

Step 1.Set the maximum emission limit based on the annual reduction rate and the BAU carbon emission.

Step 2. Subtract the reduction contribution of integrated gasification combined cycle (IGCC) and fuel cells from the result of Step 1.

Step 3. Determine the obtained volume of Step 2 as a carbon emission limit for the generation sector.

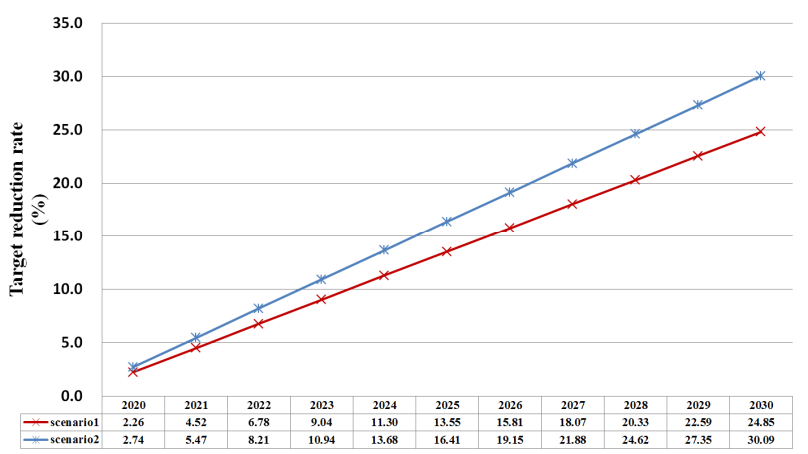

Fig. 3. Target reduction rate for 2020-2030

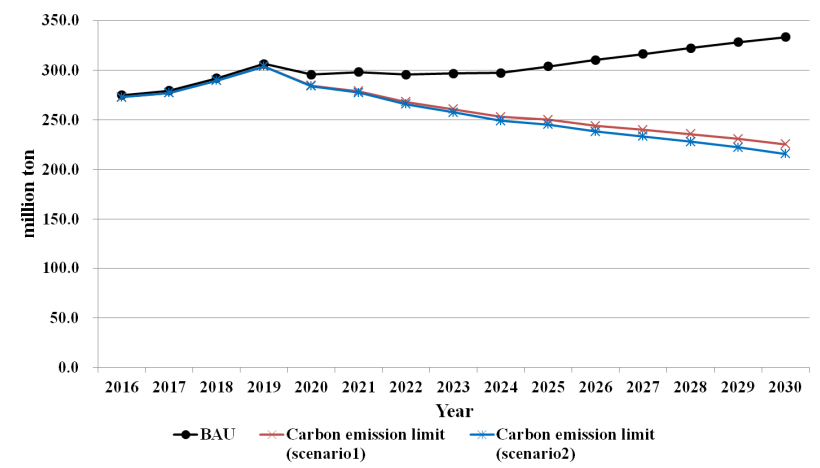

Fig. 4. "Business as usual"(BAU) carbon emissions and carbon emissions limit for the generation sector 
Table 2. Carbon emission factors by fuel type

\begin{tabular}{c|c|c|c|c}
\hline Fuel Type & \multicolumn{2}{|c|}{ Bituminous coal } & \multicolumn{2}{c}{ Anthracite coal } \\
\hline CEF (ton/MWh) & \multicolumn{2}{|c|}{0.823} & \multicolumn{2}{c}{0.914} \\
\hline Fuel Type & OIL & LNG & IGCC & Nuclear \\
\hline CEF (ton/MWh) & 0.5856 & 0.3904 & 0.67 & 0 \\
\hline
\end{tabular}

The BAU carbon emission and the maximum limit of carbon emissions applied to generation sector are illustrated in Fig. 4. Note that the emission limit declines after 2020, even though the BAU carbon emission steadily increases. The reason for this is that the growth in the carbon reduction contribution of IGCC and fuel cells exceeds the increasing carbon emissions.

\subsection{Power system description}

In the case study, the parameters for the generator cost function and TLF were obtained from data collected in February 2016. The fuel price of the generator was calculated by averaging data from 2014 to April 2016 [18]. Fixed costs of the nuclear, coal, and liquefied natural gas (LNG) generators were obtained from [12]. When applying the fixed costs of a newly installed coal generator, a value 1.5 times higher was used under the assumption of increased construction expenses [19]. Carbon emission factors for each fuel type were also adopted from [12], as listed in Table 2.

The maintenance schedule is reflected by multiplying the preventive maintenance rate by the capacity of the generator. The rate for a coal-type generator is set to 0.85 , and other types to 0.9 . To simplify the problem, the maintenance schedules of hydropower, pumping, and renewable generators were not considered. The generating outputs of renewable resources were modeled after analyzing the pattern of the outputs based on the 2014 historical data [18]. In the simulation, the outputs of renewable resources were described as a minus load. To convey practical aspects of future power scenarios, the delayed construction of facilities and the abolition of coaltype generators were also reflected. Detailed descriptions of delayed schedules can be found in [12].

New carbon capture and storage (CCS) technology that will be implemented to reduce carbon emissions was considered. CCS can lower carbon emissions by capturing carbon while consuming a portion of the fuel. Because some of the fuel is used for carbon collection, if CCS is deployed, the production unit cost of electricity will increase compared with the situation before installation. In this work, we used the following assumptions in the case study:

- The capacity of CCS-installed generators is reduced by $20 \%$.

- The calorie unit cost of the CCS installed generator is increased to $1 / 0.8$ times.

- The overnight cost of the CCS is as according to IEA
$(\$ 650 / \mathrm{kW})$.

- The $\mathrm{CO}_{2}$ capture rate is $85 \%$.

- The unit price of movement and storage of $\mathrm{CO}_{2}$ is $15,000 \mathrm{won} /$ ton.

It should be emphasized that the dispatch volume of a CCS-installed generator may be reduced significantly due to increased variable costs, and the CCS-installed generator may be pushed back in the priority rankings. In other words, the absence of an appropriate $\mathrm{CO}_{2}$ price signal in the market can cause inefficient operation of CCS-installed generators.

\subsection{Electricity market description}

It is unclear how the future electricity market will handle carbon emission constraints. In this study, we analyzed scenarios on the assumption of the following three market structures:

1) Cost Based Pool (CBP)

2) Cost Based Pool with Carbon Price (CBPP)

3) Cost Based Pool with Carbon Emission Constraint (CBPE)

The first model, denoted as CBP model, is the market model currently used in South Korea. Here, carbon emissions are completely neglected in the market clearing process, and the optimal power outputs of generators are scheduled. In real-time operation, the generating outputs are adjusted and re-dispatched with consideration of the carbon emission constraint. When calculating the payment, the scheduled output and actual dispatched output are used separately. In this model, carbon emission costs are implicitly computed by using constrained-on/constrainedoff pricing method.

The second model, denoted as CBPP, represents the market model in which market clearing is conducted with consideration of the carbon emission price. In other words, the dispatch priority is decided based on the total cost comprising variable costs and costs related to carbon emissions. In this model, energy payments to the generator owners are calculated as follows:

Energy payment $=$ SMP $\times$ generating output-carbon emission price $\times$ carbon emission volume.

The last model, denoted as CBPE, is a CBP model that includes a carbon emission constraint in the pricing mechanism. In this approach, the dispatch volumes of generators are the same as those in the second model, but the SMP is different. Although the SMP derived in the CBPP model covers the carbon emission price, the SMP in the CBPE model is determined based only on the variable costs of the generators. The generator owners receive energy payments, as follows:

Energy payment $=$ SMP $\times$ generating output 


\section{Results}

Given the conditions described in Section 3, we analyzed various effects of carbon emission constraints on the power system and the electricity market under scenarios 1 and 2. Figure 4 and 5 represent the annual carbon emission limit for the generation sector and the volume of emitted carbon with and without fuel conversion, in scenario 1 and 2, respectively. Here, fuel conversion means that a portion of coal generator power output is replaced by LNG to reduce carbon emissions and satisfy the carbon constraint.

The carbon emission limit is more stringent in scenario 2 (Fig. 6), whose carbon emission reduction target is $30.09 \%$ in 2030. In both scenarios, the carbon emission volumes exceed the allowable limit after 2023 if the carbon constraint is not imposed. In other words, the proportion of

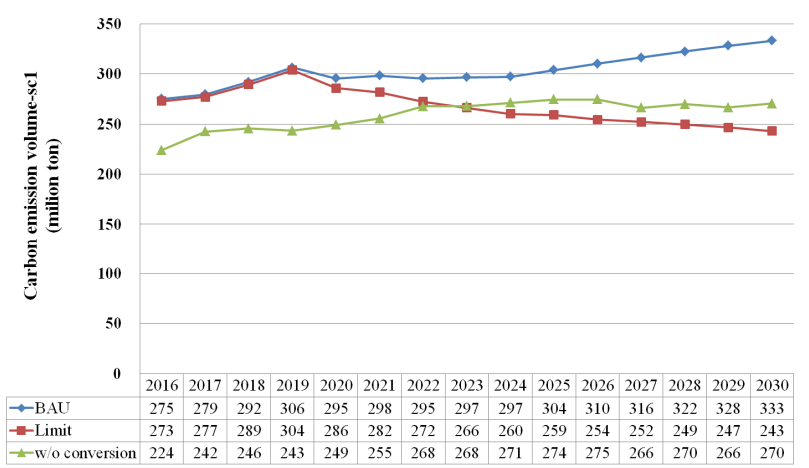

Fig. 5. Carbon emission volume in scenario 1

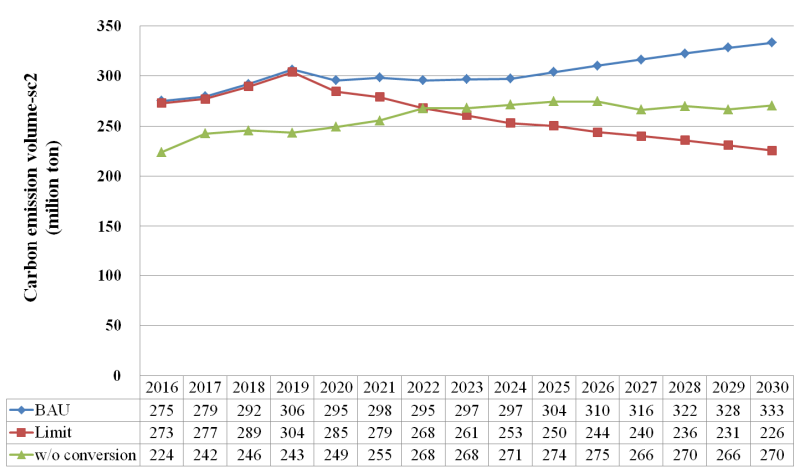

Fig. 6. Carbon emission volume in scenario 2



Fig. 7. Carbon price in scenario 1 coal generators should be reduced in the generation mix to meet the carbon emission level.

The effects of carbon emissions can also be explained through the carbon price. Because the constraint is binding after 2023, the carbon price becomes nonzero at that time. Figs. 7 and 8 represent the carbon prices in scenarios 1 and 2 , respectively.

The main difference between Figs. 7 and 8 is the price level. As the carbon reduction target is higher in scenario 2, the carbon price is also high compared with scenario 1 . The carbon price is expected to increase to $157,000 \mathrm{won} /$ ton in 2030 in scenario 2.

Next, we computed the total generation costs of the power system to supply the demand for scenarios 1 and 2 . The price effect of carbon was also measured by calculating the price increase that results from carbon emissions. The results are plotted in Figs. 9 and 10.

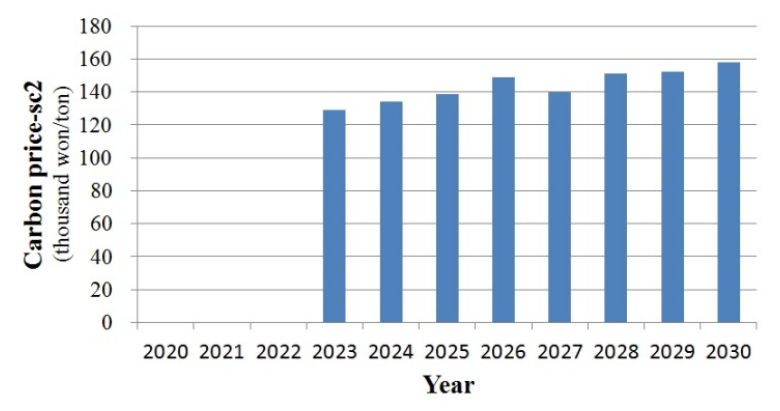

Fig. 8. Carbon price in scenario 2

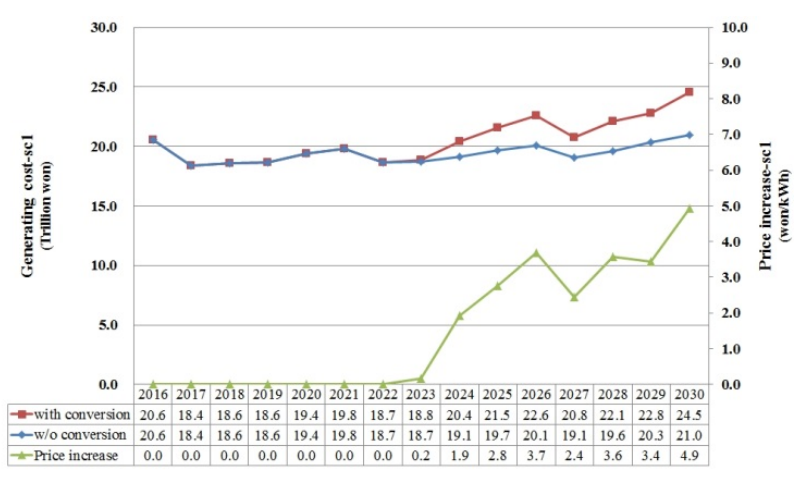

Fig. 9. Generating cost and price increase in scenario 1

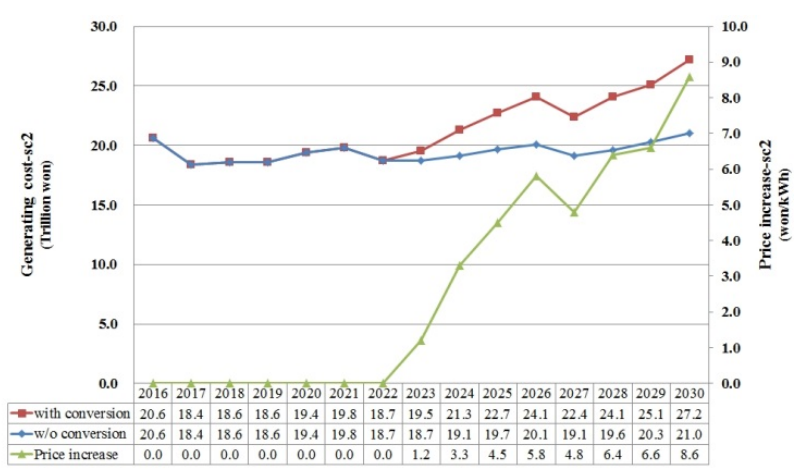

Fig. 10. Generating cost and price increase in scenario 2 
Note that the graphs are identical during the period from 2016 to 2022, but differences arise after 2023. The results consistently suggest that fuel conversion should be carried out to curtail carbon emissions after 2023. In scenario 2, an additional generation cost of 6.2 trillion won is expected to occur due to the carbon emission problem, and this result leads to an electricity tariff increase of as much as 8.6 won $/ \mathrm{kWh}$.

To examine the impact of carbon emissions on the change in generation mix, graphs of the generation mix for each year are shown in Fig. 11 without the carbon emission limit, and in Figs. 12 and 13 considering carbon emissions for scenarios 1 and 2, respectively.

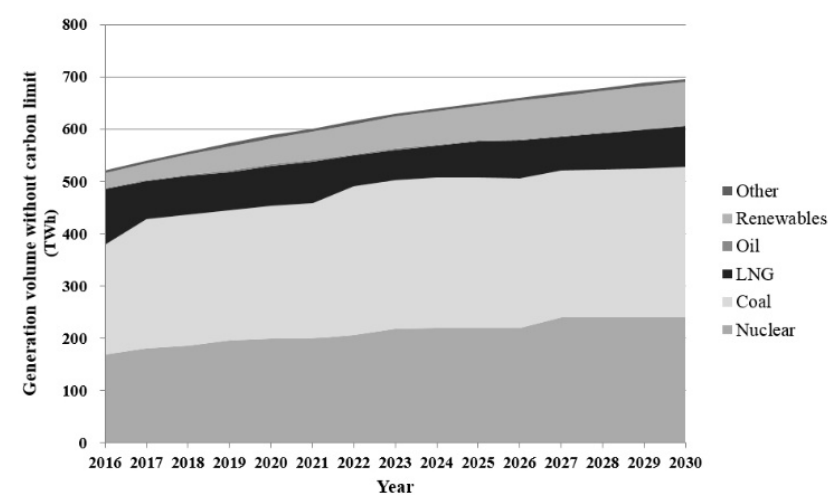

Fig. 11. Generation mix without carbon limit



Fig. 12. Generation mix with carbon limit in scenario 1

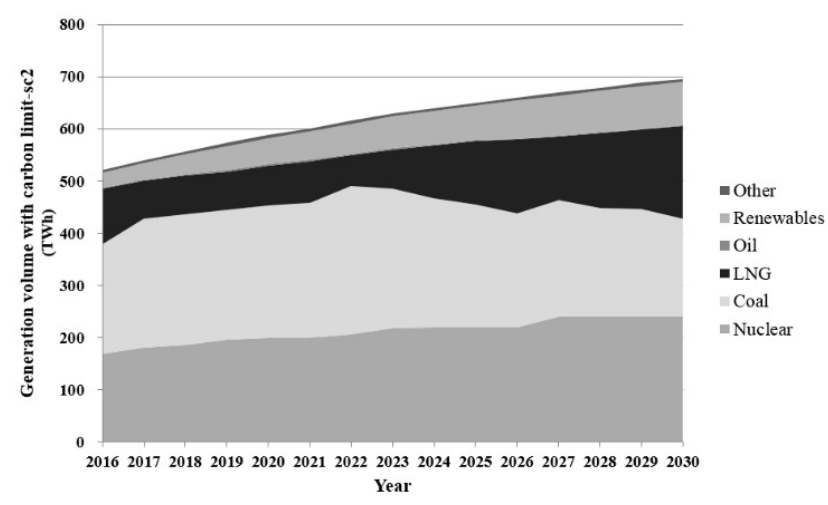

Fig. 13. Generation mix with carbon limit in scenario 2
The general shape of the graphs is the same; however, the difference between the three figures lies in the LNG and coal parts. A large amount of energy is supplied by coal generators with an increasing trend in Fig. 11, whereas the share of coal generators is reduced after 2023 in Figs. 12 and 13. As with the previous results, the decreasing coal generation share is due to the fact that carbon emissions should be restricted by fuel conversion.

Next, the SMP and profits for various generation types under the possible electricity market settlement rules are analyzed, as described in Section 3.4.

The annual SMPs are represented in Figs. 14 and 15 for scenarios 1 and 2, respectively. As shown in the figures, the SMP increases in both the CBPP and CBPE models. It can be deduced that if the market clearing process reflects the carbon price or the carbon constraint to solve the carbon emission problem, the SMP will definitely rise.

The level of the SMP is lowest in the CBP model because the carbon emission cost is not included in determining the SMP. In the CBPP model, the carbon emission price is directly considered in the calculation of the SMP, and the price level is the highest among three models. Finally, the SMP in the CBPE model is slightly higher than that in the CBP model. The reason for this is that a more expensive generator is considered in the CBPE model when calculating the SMP due to the carbon emission constraint.

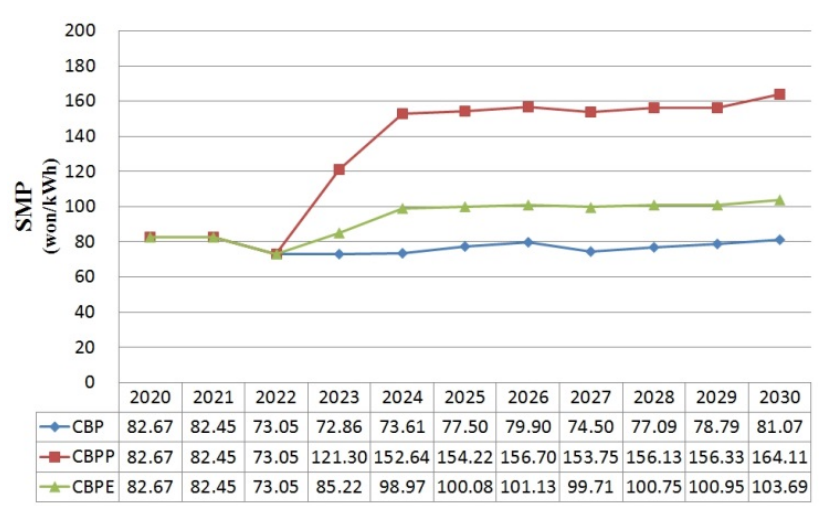

Fig. 14. SMP in scenario 1

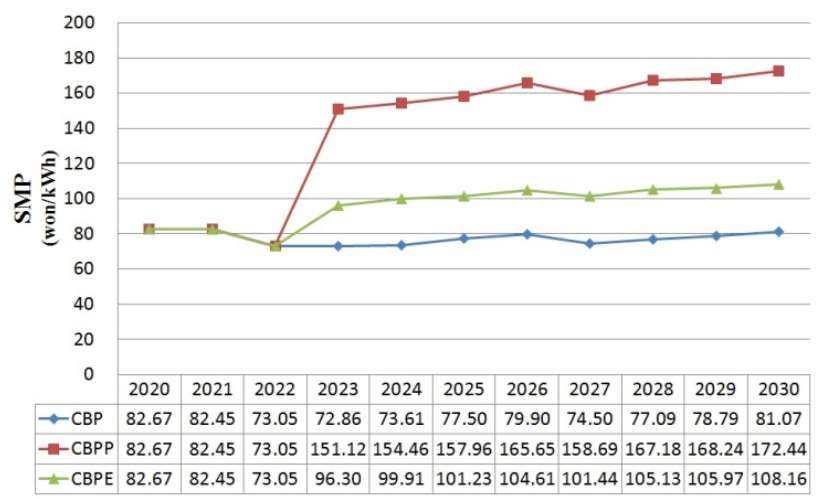

Fig. 15. SMP in scenario 2 
On the other hand, it should be recognized that the SMP in scenario 2 is higher than that in scenario 1 . This result comes from the fact that carbon emissions are more suppressed in scenario 2, and hence the carbon price is higher.

Profits for generation by type are shown in Tables 3-5. For the sake of simplicity, only the results from scenario 2 are given. Here, profit is calculated using the following equation:

\section{Profit=Energy Payment + Capacity Payment-Generation Cost - Fixed Cost}

Profits included in Table 3 are the results assuming that the current CBP market model is used continuously in the future. In this case, there is a deficit in hydraulic and pumped-storage-type generators that do not receive sufficient capacity payment. It is also expected that cogeneration type and peak generators cannot recover their

Table 3. Profits with CBP model for 2020, 2025, and 2030 (Unit: hundreds of million won)

\begin{tabular}{c|c|c|c}
\hline CBP-sc2 & $\mathbf{2 0 2 0}$ & $\mathbf{2 0 2 5}$ & $\mathbf{2 0 3 0}$ \\
\hline Other & 4,707 & 4,413 & 4,616 \\
\hline Renewables & $-33,866$ & $-47,070$ & $-55,776$ \\
\hline Hydraulic & $-1,046$ & $-1,086$ & $-1,020$ \\
\hline Pumped-storage & $-7,466$ & $-7,453$ & $-7,456$ \\
\hline Cogeneration & $-22,206$ & $-23,466$ & $-22,408$ \\
\hline Peak & $-15,657$ & $-14,655$ & $-13,867$ \\
\hline Coal & 54,173 & 40,067 & 47,567 \\
\hline Nuclear & 55,926 & 50,820 & 64,216 \\
\hline Sum & 34,565 & 1,569 & 15,873 \\
\hline
\end{tabular}

Table 4. Profits with CBPP model for 2020, 2025, and 2030 (Unit: hundreds of million won)

\begin{tabular}{c|c|c|c}
\hline CBPP-sc2 & $\mathbf{2 0 2 0}$ & $\mathbf{2 0 2 5}$ & $\mathbf{2 0 3 0}$ \\
\hline Other & 4,707 & 8,995 & 9,819 \\
\hline Renewables & $-33,866$ & 2,911 & 15,876 \\
\hline Hydraulic & $-1,046$ & 73 & 335 \\
\hline Pumped-storage & $-7,466$ & $-7,453$ & $-7,456$ \\
\hline Cogeneration & $-22,206$ & $-18,016$ & $-15,684$ \\
\hline Peak & $-15,657$ & $-11,898$ & $-4,870$ \\
\hline Coal & 54,173 & $-74,403$ & $-70,251$ \\
\hline Nuclear & 55,926 & 227,737 & 284,175 \\
\hline Sum & 34,565 & 127,946 & 211,945 \\
\hline
\end{tabular}

Table 5. Profits with CBPE model for 2020, 2025, and 2030 (Unit: hundreds of million won)

\begin{tabular}{c|c|c|c}
\hline CBPE-sc2 & $\mathbf{2 0 2 0}$ & $\mathbf{2 0 2 5}$ & $\mathbf{2 0 3 0}$ \\
\hline Other & 4,707 & 5,764 & 6,159 \\
\hline Renewables & $-33,866$ & $-33,936$ & $-36,451$ \\
\hline Hydraulic & $-1,046$ & -875 & -752 \\
\hline Pumped-storage & $-7,466$ & $-7,453$ & $-7,456$ \\
\hline Cogeneration & $-22,206$ & $-17,964$ & $-15,548$ \\
\hline Peak & $-14,135$ & $-11,891$ & $-4,736$ \\
\hline Coal & 54,173 & 69,765 & 50,282 \\
\hline Nuclear & 55,926 & 102,999 & 129,440 \\
\hline Sum & 36,087 & 106,409 & 120,938 \\
\hline
\end{tabular}

fixed costs due to the low level of the capacity factor.

The results based on the CBPP model where the carbon price is reflected in the SMP calculation, are shown in Table 4. Compared with Table 3, profits for coal generators fall steeply. Instead, deficits for cogeneration type and peak generators decrease. It is interesting to note that renewables and nuclear generators derive obvious benefits because these types of generation do not produce any carbon emissions.

Table 5 shows the results with the CBPE model. In this case, the carbon price and dispatched volume of generators are identical to that of the CBPP model, whereas the SMP is computed based only on the variable costs of the generators. It can be seen that the profits for coal generators are nonnegative, in contrast to the results shown in Table 4.

\section{Conclusion}

In this paper, an investigation of the impact of limiting carbon emissions on the power system and the electricity market is undertaken, assuming plausible scenarios for the future system. The proposed mathematical formulation applies a carbon emission constraint based on mitigation targets for the power sector. A case study of the Korean power system was conducted; possible techniques to resolve the carbon problem were tested.

The preliminary results of this study show that the carbon emission reduction target cannot be reached after year 2023 without fuel conversion. Energy supplied by relatively inexpensive coal-type generators will need to be curtailed, leading to an increase in total generation costs in the power system, and in the market price. Moreover, the simulation results show that the SMP of the market and profits for generation will vary widely according to the electricity market model. In particular, if a carbon emission price (CBPP) model is applied in the market to determine the SMP, owners of coal-type generators will inevitably face large deficits. Therefore, selection of an adequate compensation method will become increasingly important.

\section{Acknowledgements}

This work was supported by the BK21 Plus Program (Next Generation Training Program for Statistical Sciences, Department of Statistics, Seoul National University) funded by the Ministry of Education, Korea (No. 22A20151713442).

\section{References}

[1] P. Agreement, "United Nations Framework Convention on Climate Change," Paris, France, 2015.

[2] U. Secretariat, "Synthesis Report on the Aggregate 
Effect of the Intended Nationally Determined Contributions," in Bonn, Germany: United Nations Framework Convention on Climate Change, 2015.

[3] B. L.P., "How Ambitious are the Post-2020 Targets? Assessing the INDCs: comparing apples with oranges," 2015.

[4] GGCC, "The Carbon Budgets That Will Prevent the Average Temperature of the Earth's Surface from Increasing by More than $2^{\circ} \mathrm{C}$ when Compared with the Temperature of the Pre-industrial Era.," 2015.

[5] Y. Ha, J. Joo, M. Kang, T. Lah, and J. Jang, "Social conflicts and policy-making in Korea: Interpretation of policy failures through a public discourse perspective," International Review of Administrative Sciences, vol. 75, pp. 649-664, 2009.

[6] T. Priestley and G. W. Evans, "Resident perceptions of a nearby electric transmission line," Journal of Environmental Psychology, vol. 16, pp. 65-74, 1996.

[7] N. F. Pidgeon, I. Lorenzoni, and W. Poortinga, "Climate change or nuclear power - No thanks! A quantitative study of public perceptions and risk framing in Britain," Global Environmental Change, vol. 18, pp. 69-85, 2008.

[8] P. Ekins, G. Anandarajah, and N. Strachan, "Towards a low-carbon economy: scenarios and policies for the UK," Climate Policy, vol. 11, pp. 865-882, 2011.

[9] C. Erdmenger, H. Lehmann, K. Müschen, J. Tambke, S. Mayr, and K. Kuhnhenn, "A climate protection strategy for Germany - 40\% reduction of $\mathrm{CO}_{2}$ emissions by 2020 compared to 1990," Energy Policy, vol. 37, pp. 158-165, 2009.

[10] K. Shimada, Y. Tanaka, K. Gomi, and Y. Matsuoka, "Developing a long-term local society design methodology towards a low-carbon economy: An application to Shiga Prefecture in Japan," Energy Policy, vol. 35, pp. 4688-4703, 2007.

[11] "Carbon Pollution Reduction Scheme: Australia's Low Pollution Future,” A. Government, Ed., ed, 2008.

[12] Ministry of Trade, Industry and Energy, "The 7th Basic Plan for Long-term Electricity Supply and Demand(2015-2029)," 2015.

[13] D. G. Luenberger, Introduction to linear and nonlinear programming vol. 28: Addison-Wesley Reading, MA, 1973.

[14] M. Carrión and J. M. Arroyo, "A computationally efficient mixed-integer linear formulation for the thermal unit commitment problem," IEEE Transactions on power systems, vol. 21, pp. 1371-1378, 2006.

[15] C. K. Simoglou, P. N. Biskas, and A. G. Bakirtzis, "Optimal self-scheduling of a thermal producer in short-term electricity markets by MILP," IEEE Transactions on Power Systems, vol. 25, pp. 19651977, 2010.

[16] F. Capitanescu, J. M. Ramos, P. Panciatici, D. Kirschen, A. M. Marcolini, L. Platbrood, et al.,
"State-of-the-art, challenges, and future trends in security constrained optimal power flow," Electric Power Systems Research, vol. 81, pp. 1731-1741, 2011.

[17] Ministry of Trade, Industry and Energy, "Korea Energy Master Plan-outlook \& policies to 2035," 2014.

[18] Korea Power Exchange (KPX). (2016). Electric Power Statistics Information System. Available: http://epsis.kpx.or.kr/epsis/

[19] EIA, U., "Updated capital cost estimates for electricity generation plants," US Energy Information Administration, Office of Energy Analysis, Washington, DC, USA, 2010.



Changseob Kim He received Ph.D degree in electrical engineering from Seoul National University. His research interests are energy policy, smart grid, climate change.

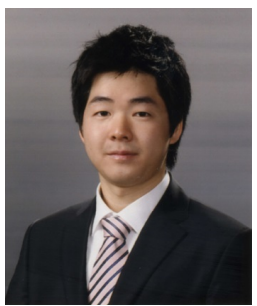

Hyeongon Park He received Ph.D degree in Electrical Engineering and Computer Science from Seoul National University. He is currently a postdoctoral researcher at Seoul National University. His research interests include electric power network economics, uncertainty modeling and power system reliability. 